\title{
Current Status of Schistosomiasis in Egypt: Parasitologic and Endoscopic Study in Sharqia Governorate
}

Corresponding author:

Tarik Zaher

Mobile:

0020101855393 e mail

:tareqzaher@zu.edu.eg

Received:15/1/2011

Accepted after

revision: $17 / 7 / 2011$

Keywords:

Schistosomiasis ; Egypt;

Parasitologic;

Endoscopic.

Tarik Zaher', Mohieddin Abdul-Fattah², Amany Ibrahim³, Hossam Salah ${ }^{4}$, Mona El-Motyam², Walid A Abdel-Dayem ${ }^{1}$, Mohamed M Refaey ${ }^{1}$.

${ }^{I}$ Endemic and Tropical Medicine Department, Faculty of Medicine, Zagazig University, Zagazig,

Egypt.

${ }^{2}$ Parasitology Department, Faculty of Medicine, Zagazig University, Zagazig, Egypt.

${ }^{3}$ Internal Medicine Department, Faculty of Medicine, Zagazig University, Zagazig, Egypt.

${ }^{4}$ Clinical Pathology Department, Faculty of Medicine, Zagazig University, Zagazig, Egypt.

Background and study aim: Schistosomiasis was endemic in Egypt since the ancient times. It was traditionally the most important public health problem. This study aimed to evaluate the current status of schistosomiasis in Sharkia governorate, Egypt.

Patients and methods: Over 5 years (20052010), schistosome eggs were sought by sedimentation techniques in stool and urine samples of 30,000 outpatient persons attending the Tenth of Ramadan Charity Hospital, Tenth of Ramadan City, Sharqia Governorate, Egypt and in histologically processed rectal biopsy samples from patients with negative coproscopy. These samples were obtained by lower endoscopy from 250 patients out of them.

\section{INTRODUCTION}

Schistosomiasis is one of the most widespread parasitic infections of man [1]. Egypt is a cradle of civilization, but has been plagued by schistosomiasis since at least the Middle Kingdom $\begin{array}{ll}\text { period } \quad(1,500 & \mathrm{BC})[2] . \quad \text { It was }\end{array}$ traditionally the most important public health problem[3,4]. This study aimed to evaluate the current status of schistosomiasis in Egypt.

\section{PATIENTS AND METHODS Over 5 years (2005-2010),} schistosome eggs were sought by sedimentation technique in stool and urine samples of 30,000 outpatient persons attending the Tenth of Ramadan Charity Hospital, Tenth of Ramadan City, Sharqia Governorate, Egypt.

Tenth of Ramadan City is an industrial urban large city in Sharkia
Results: Eggs of Schistosoma haematobium were encountered in urine samples of 6 persons $(0.02 \%)$ of the 30,000 outpatients.Eggs of Schistosoma mansoni were encountered in stool samples of 99 persons $(0.33 \%)$ of the 30,000 outpatients. Eggs were also found in 12 persons (4.8\%) (2 with living Schistosoma mansoni eggs, 1with dead Schistosoma haematobium eggs and 9 with dead Schistosoma mansoni eggs) out of the 250 patients contributing to rectal biopsy samples.

Conclusion: The present findings revealed a decrease in the prevalence of schistosomiasis that may be explained by the current policy of schistosomiasis control in Egypt.
Governorate but most of it's inhabitants are immigrants of other Egyptian Governorates endemic with schistosomiases.

250 patients with negative coproscopy were examined by lower endoscopy using Olympus CF160AL colonoscope (Olympus Company Ltd, Japan). Rectal biopsy samples were obtained and examined microscopically. Informed consents were obtained from all patients.

Sedimentation technique of urine: $50 \mathrm{ml}$ urine samples were left to sediment spontaneously. Small drop of the sediment was examined microscopically.

Sedimentation technique of stool: The technique standardized by Hoffman et al.[5] involves the filtration of saline-feces mixture through a metal sieve to remove larger 
fecel residues and to allow the remainder to sediment spontaneously. A sample of the sedimented material is then examined between a slide and cover slip.

\section{RESULTS}

Eggs of Schistosoma haematobium were encountered in urine samples of 6 ones $(0.02 \%)$ of the 30,000 outpatients. Eggs of Schistosoma mansoni were encountered in stool samples of 99 ones $(0.33 \%)$ of the 30,000 outpatients.

Eggs were also found in 12 ones (4.8\%) (2 with living Schistosoma mansoni eggs, 1 with dead Schistosoma haematobium eggs and 9 with dead Schistosoma mansoni eggs) out of the 250 patients contributing to rectal biopsy samples.

Table (1) : Results.

\begin{tabular}{|l|c|c|c|c|c|c|c|c|}
\hline \multirow{2}{*}{} & \multicolumn{3}{|c|}{ Patients with S. mansoni eggs } & \multicolumn{3}{c|}{ Patients with S. haematobium eggs } \\
\cline { 2 - 9 } & \multicolumn{2}{|c|}{ Living } & \multicolumn{2}{|c|}{ Dead } & \multicolumn{2}{c|}{ Living } & \multicolumn{2}{c|}{ Dead } \\
\cline { 2 - 9 } & $\mathrm{N}$ & $\%$ & $\mathrm{n}$ & $\%$ & $\mathrm{n}$ & $\mathrm{n}$ & - \\
\hline $\begin{array}{l}\text { Stool samples } \\
\mathrm{n}=30,000\end{array}$ & 99 & 0.33 & - & - & - & - & - \\
\hline $\begin{array}{l}\text { Urine samples } \\
\mathrm{n}=30,000\end{array}$ & - & - & - & - & 6 & 0.02 & & \\
\hline $\begin{array}{l}\text { Rectal biopsy samples } \mathrm{n}= \\
250\end{array}$ & 2 & 0.8 & 9 & 3.6 & - & & - & 0.4 \\
\hline
\end{tabular}

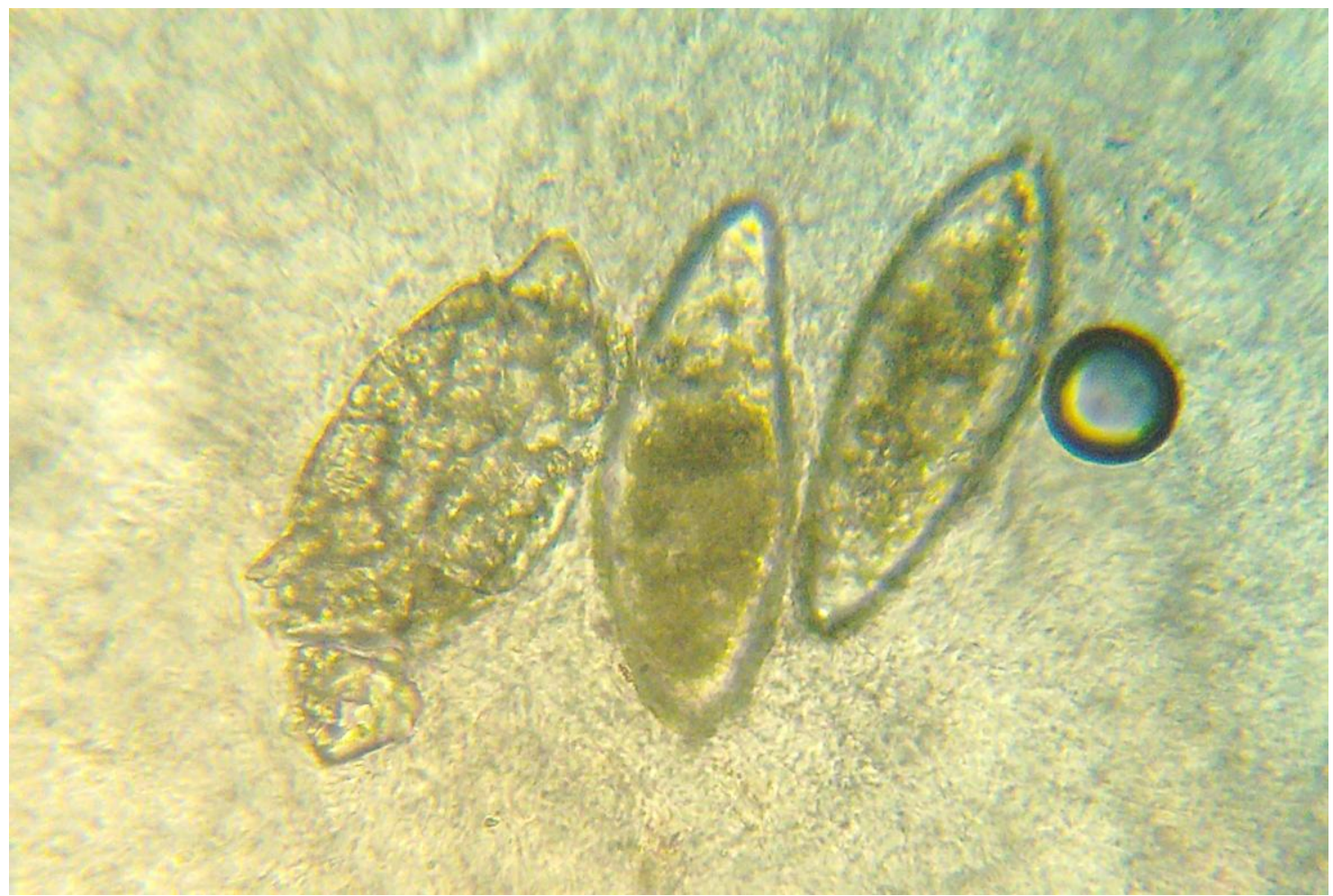

Figure (1): 3 dead Shistosoma haematobium eggs in rectal biopsy samples

\section{DISCUSSION}

In this study; eggs of Schistosoma mansoni were encountered in $0.33 \%$ of stool samples and eggs of Schistosoma haematobium were encountered in $0.02 \%$ of urine samples. Schistosoma eggs were also found in $4.8 \%$ of patients contributing to rectal biopsy samples. In agreement with our results; Rabello [6] who concluded that a single rectal biopsy resulted in the diagnosis of more individuals than a single fecal examination by Kato/Katz method.

In 1937; Scott [7] reported the results of parasitologic examination performed on 2 million patients seen between 1932 and 1934 in government treatment centers, and on results of examination of stool and urine samples collected from 40,000 subjects. He found that $60 \%$ of the rural population in north and 
east of the Nile delta were infected with $S$. haematobium and about the same proportion was infected with $S$. mansoni. In the south central delta, the prevalence of $S$. haematobium was $60 \%$, but only $6 \%$ had S. mansoni. S. mansoni was not found in Upper Egypt and S. haematobium was found in $60 \%$ of patients in areas under perennial irrigation. In areas under basin irrigation, only 5\% were infected by $S$. haematobium.

An increase in the prevalence of $S$. mansoni infections with their snails and decrease in prevalence of $S$. haematobium infections with their snails were noticed after construction of the High Dam in the 1960s because of reclamation of the land, conversion of annual flooding into perennial irrigation and other ecological factors as changes in the water-flow pattern [8]. In 1977, El Alamy and Cline [9] found that the prevalence of $S$. mansoni infection was $40.5 \%$, and the prevalence of $S$. haematobium infection was $27 \%$ in Qalyub region in the south of Nile Delta. In 1979; Abdel-Wahab et al.[10] found that the prevalence of Schistosoma mansoni infection had increased from $3.2 \%$ to $73 \%$, whereas $S$. haematobium infection which had very common in 1935 (74\%), had almost disappeared $(2.2 \%)$ in the same village in the Nile delta surveyed by Scott in 1935 .

In 1982, King et al.[11] found that the prevalence of Schistosoma haematobium in six rural villages of the Qena governorate was $37.1 \%$.

In the nineties, El-Kohby et al.[4] found that the prevalence of $S$. mansoni and $S$. haematobium in Ismailia governorate was $42.9 \%$ and $3.5 \%$ respectively, Kafr-El-Sheikh; $39.1 \%$ and $2.5 \%$, Gharbia: $37.7 \%$ and $2.06 \%$, Monofia: $28.49 \%$ and 5.5\%, Qalubia: $17.47 \%$ and 1.53\%, Fayoum: $4.3 \%$ and $9.95 \%$, Minya: $1.04 \%$ and $8.47 \%$, Assiut: $0.42 \%$ and $6.63 \%$ and Qena: $0.44 \%$ and $7.04 \%$.

In this study, the prevalence of $S$. mansoni and $S$. haematobium depending on stool and urine examination in Tenth of Ramdan Charity Hospital, Tenth of Ramadan city which is an urban city in Sharqia Governorate was $0.33 \%$ and $0.02 \%$ respectively. In comparison with our study; el-Badawy et al.[12] in 1996 who found that the prevalence of $S$. mansoni and $S$. haematobium depending on stool and urine examination in urban Sharqia Governorate was $6.8 \%$ and $0.09 \%$.

In this study, $S$. haematobium eggs were found in rectal biopsy sample of one patient. In agreement with our finding; Abdel-Wahab et al.[13] who found a mild grade of periportal fibrosis, hepatomegaly and splenomegaly in school children with $S$. haematobium infection in a village in the Fayoum.
Conclusion: The present findings revealed a decrease in the prevalence of schistosomiasis that may be explained by the current policy of schistosomiasis control in Egypt. Further studies in different localities in Egypt are needed to reflect the actual prevalence of schistosomiasis.Much more strict programs to control schistosomiasis hoping at complete eradication of this disease are recommended.

Conflicts of interest:Non declared.

Funding:Non

Ethical approval:Approved.

\section{REFERENCES}

1. Iarotski L, Davis A. The Schistosomiasis problem in the world: Results of a WHO questionnaire survey. Bulletin of the World Helath Orgaization 1981; 59 (1): 115-127.

2. Abdel-Wahab M. Schistosomiasis in Egypt 1982; Boca Raton, FL: CRC Press.

3. Strickland G. Liver disease in Egypt: hepatitis C superseded schistosomiasis as a result of iatrogenic and biological factors. Hepatology 2006; 43 (5): 915-22.

4. El-Khoby, Galal N, Fenwick A, Barakat R, El-Hawey A, Nooman Z, Habib M, Abdel-Wahab F, Gabr N, Hammam H, Hussiein M, Mikhail N, Cline B, Strickland T. The epidemiology of schistosomiasis in Egypt: Summary findings in nine governorates. Am J Trop Med Hyg 2000; 62 (2)s: 88-99

5. Hoffman W, Pons J, Janer J. Sedimentation concentration method in schistosomiasis mansoni. Puerto Rico J Publ Health Trop Med 1934; 9: 283-298.

6. Rabello A. Parasitological diagnosis of schistosomiasis mansoni: fecal exmaination and rectal biopsy. Mem Inst Oswaldo Cruz Rio de Janeiro 1992; 87 (Suppl. IV): 325331.

7. Scott J. The incidence and distribution of human schistosomiasis in Egypt. Am J Hyg 1937; 25: 566-614.

8. Malek E. Effect of the Aswan High Dam on Prevalence of schistosomiasis in Egypt. Trop Geogr Med 1975; 27 (4): 359-64.

9. El Alamy M, Cline B. Prevalence and intensity of Schistosoma haematobium and S. mansoni infection in Qalyub, Egypt. Am J Trop Med Hyg 1977; 26 (3): 470-2.

10. Abdel-Wahab M, Strickland G, El-Sahly A, El-Kady N, Zakaria S, Ahmed L. Changing pattern of schistosomiasis in Egypt 1935-79. Lancet 1979; 4 (2): 242-4.

11. King C, Miller F, Hussein M, Barkat R, Monto A. Prevalence and intensity of Schistosoma haematobium infection in six villages of upper Egypt. Am J Trop Med Hyg 1982; 31 (2): 320-7.

12. el-Badawy A, EL-Moghazy M, Koura S, Ragab H, Sherif N. Schistosomiasis status in urban Sharkia Governorate, Egypt: Prevalence and intensity of infection. J Egypt Soc Parasitol 1996; 26 (3): 733-42.

13. Abdel-Wahab M, Esmat G, Ramzy I, Fouad R, AbdelRahman M, Yosery A, Narooz S, Strickland G. Schistosoma haematobium infection in Egyptian school children: Demonstration of both hepatic and urinary tract morbidity by ultrasonogrpahy. Trans $R$ Soc Trop Med Hyg 1992; 86 (4): 406-9. 